\title{
EN TORNO A CADUCIDAD DE ACCIÓN RETRACTUAL ARRENDATICIA URBANA (COMENTARIOS A LA SENTENCIA DEL TRIBUNAL SUPREMO DE 16 DE MARZO DE 1.992. SALA PRIMERA)
}

\author{
Dr. Luis Fernando Saura \\ Profesor Titular de Derecho Civil.
}

\section{SENTENCIA}

Antecedentes de hecho.

PRIMERO.-EI Procurador D. Miguel Angel Carbonell Cuxart en nombre y representación de Doña Nuria Batet Martí, formuló ante el Juzgado de Primera Instancia número Cuatro de Barcelona, demanda de juicio de retracto arrendaticio contra D. Anastasio Pascual Ortega, alegó los hechos que en síntesis son: La actora es arrendaticia del local de negocio «comercial bajos» sito en la calle Francisco Aranda 37 de Barcelona, por contrato arrendaticio de fecha 29 de Junio de 1987 por un plazo de diez años. El 13 de Mayo de 1988, $D^{\mathbf{a}}$ María Josefa Jodar Arquero, propietaria del local, lo vendió a D. Anastasio Pascual Ortega en la cantidad de cinco millones de pesetas. De la indicada compra-venta tuvo conocimiento la actora por conducto notarial de 18 de Mayo de 1988, consignando en el Juzgado la cantidad de dos millones seiscientas ochenta mil seiscientas cincuenta y ocho pesetas, cantidad que reconocía la vendedora haber recibido con anterioridad del comprador, formulando expreso ofrecimiento formal de todos los gastos legítimos. Alegó los fundamentos de derecho que constan en autos y terminó suplicando del Juzgado en su día se dicte sentencia por la que se declare el derecho de Doña Nuria Batet Martí a retraer el local de negocio adquirido por el demandado $D$. Anastasio Pascual Ortega, condenando a éste a que en el breve término que al efecto se señale otorgue escritura de compraventa a favor de la actora, bajo apercibimiento de otorgarla de oficio si no la verificara, así como a que desaloje y deje vacua, libre y expedita dicha vivienda, bajo apercibimiento de lanzamiento si no la desaloja dentro del plazo legal; a cuyo fin se confiera traslado de esta demanda a $D$. Anastasio Pascual Ortega, luego que se presente la correspondiente certificación del acto de conciliación, con expresa imposición al demandado de las costas de este juicio. Por escrito de 11 de Noviembre de 1988, se amplió a la demandada Da Ana María Pascual Gonzalo. 
SEGUNDO.- Admitida la demanda y emplazados los demandados, se personó en el Juzgado el Procurador D. Antonio Prades Espot en nombre y representación de D. Anastasio Pascual Ortega, quien formuló la excepción dilatoria de falta de personalidad en el demandado, por lo que suplicó al Juzgado dicte auto por el que se tenga por admitida dicha excepción, sin perjuicio del derecho del demandante de ejercitarlo contra $D^{\mathbf{a}}$ Ana María Pascual Gonzalo, con imposición de costas al demandante dada su manifiesta temeridad y mala fe. Por providencia de fecha 10 de Noviembre de 1988, denegó el anterior escrito. Contestó a la demanda oponiendo los hechos y fundamentos de derecho que constan en autos y terminó suplicando del Juzgado, se dicte sentencia por la que se absuelva a dicho demandado de las pretensiones contenidas en la demanda promovida en su contra, con imposición de las costas al demandante.

TERCERO.-La Procuradora $D^{\mathrm{a}}$ Ana Vilanova Siberta, en nombre y representación de $D^{a}$ Ana María Pascual Gonzalo, contestó a la demanda, oponiendo los hechos y fundamentos de derecho que constan en autos y terminó suplicando al Juzgado se declare no haber lugar al retracto arrendaticio que se pretende, absolviendo a su representada de las pretensiones contenidas en la demanda promovida en su contra, con imposición de costas a la demandante.

CUARTO.- Recibido el pleito a prueba, se practicó la que propuesta por las partes fue declarada pertinente y figura en las respectivas piezas separadas. Unidas a los autos las pruebas practicadas se entregaron los mismos a las partes para conclusiones.

QUINTO.- El Ilmo. Sr. Magistrado-Juez de Primera Instancia dictó sentencia en fecha 14 de Febrero de 1989 cuyo fallo es el siguiente: «Que desestimando la demanda interpuesta por Doña Nuria Batet Martí contra Don Pascual Ortega no dando lugar a los pedimentos en ella contenidos y con expresa imposición de costas a la parte actora. Asimismo estimo la demanda interpuesta por Doña Nuria Batet Martí, contra Doña Ana María Pascual Gonzalo, y, en consecuencia, declaro el derecho de Doña Nuria Batet Martí, previo abono a la demandada de la suma de dos millones seiscientas ochenta mil seiscienta cincuenta y ocho pesetas más novecientas veinte mil seiscientas trece pesetas, al retracto arrendaticio respecto del local de negocios sito en la calle Francisco de Aranda número 37-39 de esta Ciudad, el cual se tiene por ejercitado, condenándose a la demandada a que en el término de un mes a contar desde la firmeza de esta sentencia, otorgue la escritura pública de compraventa a favor de la actora en los mismos términos que el contrato por ella suscrito con Doña María Josefa Jodar Arquero en fecha trece de mayo de 
1988, bajo apercibimiento de otorgarla de oficio si no lo efectuare, siendo los gastos que de dicha escritura se deriven de cargo de Doña Nuria Batet Martí. Asimismo se condena a Doña Ana María Pascual al pago de las costas causadas.»

SEXTO.- Apelada la sentencia de primera instancia, la Sección Once de la Audiencia Provincial de Barcelona dictó sentencia en fecha 19 de Octubre de 1989, cuya parte dispositiva a tenor literal es la siguiente: «Que estimándose el recurso de apelación interpuesto por la representación de $\mathrm{D}^{\mathrm{a}}$ Ana María Pascual Gonzalo contra la Sentencia dictada con fecha catorce de Febrero del corriente año por el Iltrmo. Sr. Juez del Juzgado de $1^{\text {a }}$ Instancia $n^{0}$ cuatro de Barcelona en autos de Retracto Arrendaticio Urbano $n^{0} \mathbf{7 4 0} / 88$ instados por Doña Nuria Batet Martí, contra D. Anastasio Pascual Ortega y Dª Ana María Pascual Gonzalo, procede desestimar todos los pedimentos que se contienen en escrito de demanda, imponiendo a la parte actora las costas causadas en primera instancia y sin esepcial pronunciamiento en cuanto a las costas de esta alzada.»

SÉPTIMO.- EI Procurador D. Eduardo Morales Price en nombre y representación de $D^{a}$ Nuria Batet Martí, interpuso recurso de casación con apoyo en los siguientes motivos: Primero.- Al amparo de lo dispuesto por el art. 1692, párrafo $5^{\circ}$ de la L.E.C., por infracción del art. 48, párrafo $2^{\circ}$ de la Ley de Arrendamientos Urbanos. Segundo.- Al amparo del art. 1692, 5-, de la L.E.C., por no haber aplicdo la sentencia recurrida el art. 1618 de la Ley de E.C. Tercero.- Se interpone al amparo del art. 1692, 5 de la L.E.C. por no haber aplicado la sentencia recurrida lo dispuesta en el art. 11, párrafo $3^{\circ}$ de la Ley Orgánica del Poder Judicial, en relación con el art. 24 de la Constitución vigente.

OCTAVO.- Admitido el recurso y evacuado el trámite de instrucción, se señaló para la celebración de la vista, el día 27 de Febrero de 1992.

HA SIDO PONENTE EL MAGISTRADO EXCMO. SR. D. Francisco Morales Morales.

\section{FUNDAMENTOS DE DERECHO}

PRIMERO.- Para el estudio del presente recurso se estima necesario dejar consignados los siguientes antecedentes previos: $1^{\mathbf{0}} \mathrm{D}^{\mathbf{a}}$ Nuria Batet Martí es la 
arrendataria del local de negocio sito en los bajos de la casa número 37-39 de la calle Francisco Aranda, de Barcelona. 2º Mediante escritura pública de compraventa, de fecha 13 de Mayo de 1988, autorizada por el Notario de Barcelona D. José Solís y Lluch (número 1390 de su protocolo), D. Anastasio Pascual Ortega, actuando como representante de su hija $D^{a}$ Ana María Pascual Gonzalo, compró para ésta el mencionado local de negocio a la propietaria del mismo, por el precio de cinco millones de pesetas, cuyo pago se hizo efectivo con las retenciones que se expresan en dicha escritura, en la que se hace constar: «Estado arrendaticio: El descrito local se halla arrendado a $D^{\mathbf{a}}$ Nuria Batet Martí» y en cuya cláusula A) del otorgamiento se expresa: « $D^{\mathbf{a}}$ María-Josefa Jodar Arquero vende el descrito local al otro compareciente D. Anastasio Pascual Ortega que lo compra para su representada, su hija $D^{\mathbf{a}}$ Ana-María Pascual Gonzalo, con cuanto a dicho local sea inherente y accesorio». $3^{\circ} \mathrm{A}$ petición de los otorgantes de la referida escritura pública de compraventa, el Notario autorizante de la misma la notificó, por correo certificado con acuse de recibo, a la arrendatario $D^{\mathbf{a}}$ Nuria Batet Martí; la cual recibió dicha notificación el día 18 de Mayo de 1988. $4^{\circ}$ Con base en la expresada notificación, $D^{a}$ Nuria Batet Martí, con fecha 15 de Julio de 1988, promovió contra D. Anastasio Pascual Ortega el proceso de que este recurso dimana, en el que ejercitó la acción de retracto que le concede el artículo 48 de la Ley de Arrendamientos Urbanos con respecto al referido local, para lo cual consignó en el Juzgado el precio que, efectivamente, había pagado D. Anastasio Pascual Ortega, en representación de su hija $D^{\mathbf{a}}$ Ana-María Pascual Gonzalo y, además, manifestó en la demanda: «...expreso of recimiento formal de abonar todos los gastos legítimos. Asimismo, constituyó formal promesa de pagar todos los conceptos que constan en las retenciones que expresa el contrato de compraventa o de hacerlos efectivos a D. Anastasio Pascual Ortega, en el caso de que ya hubiera pagado alguno de ellos». 5 El demandado D. Anastasio Pascual Ortega se personó en el proceso y, sin contestar a la demanda, adujo, con carácter previo, la excepción dilatoria de falta de personalidad en el demandado, por no tener el carácter con que se le demanda, alegando que él no era el comprador del expresado local de negocio, sino que lo era su hija y representada $D^{\underline{a}}$ Ana-María Pascual Gonzalo. 6 ${ }^{\circ}$ Ante dicha alegación y antes de que D. Anastasio Pascual Ortega evacuara el trámite de contestación, la actora $D^{\mathrm{a}}$ Nuria Batet presentó nuevo escrito en el que alegando que, si bien había identificado plenamente el local objeto de retracto y había consignado el precio efectivamente pagado por la compra, había padecido error al identificar a la compradora, confundiendo a ésta con su padre y representante, por lo que amplió su demanda, dirigiendo ésta contra $D^{\mathrm{a}}$ Ana-María Pascual Gonzalo. $7^{0}$ En el escrito de contestación a la demanda, la referida demandada ( $D^{\mathrm{a}}$ Ana-María Pascual Gonzalo) se opuso a la misma, alegando: a) Caducidad de la acción de retracto, por no haber sido 
ejercitada la misma contra ella, como compradora, dentro del plazo legalmente establecido (sesenta días desde el conocimiento de la venta); b) Inexistencia del derecho de retracto por renuncia previa al mismo por el demandante y c) Incumplimiento de los requisitos para retraer, por no haber consignado la demandante los gastos del contrato y otros pagos legítimos hechos para la venta (honorarios de la Notaría, impuesto de transmisiones patrimoniales, arancel del Registro de la Propiedad), aparte de que ella (la demandada), con posterioridad al otorgamiento de la escritura pública de compraventa había hecho pago de algunas de las cantidades retenidas (gastos originados por la reclamación judicial del préstamo y amortización de la hipoteca de Enero a Diciembre de 1987 y de 1988). $8^{\circ}$ La sentencia de primera instancia, desestimando las tres referidas causa de oposición aducidas por la demandada, estimó la demanda y dio lugar al retracto. 9o Apelada dicha sentencia por la demandada $\mathrm{D}^{\mathbf{a}}$ AnaMaría Pascual Gonzalo, la Sección Once de la Audiencia Provincial de Barcelona dictó otra por la que desestimando expresamente la causa de oposición antes señalada bajo el apartado b) —renuncia previa al derecho de retracto- y sin entrar a conocer de la señalada bajo el apartado c) -irregular consignación hecha por la demandante-, estimó la causa de oposición reseñada bajo la letra a) —caducidad de la acción-, por entender, como «ratio decidendi» de su fallo, que si bien la demanda formulada contra D. Anastasio Pascual Ortega lo había sido dentro del plazo legal de sesenta días, sin embargo no lo fue, dentro de dicho plazo, contra la compradora $D^{\mathrm{a}}$ Ana-María Pascual Gonzalo, por lo que, entendiendo producida la caducidad de la acción, revoca la sentencia de primera instancia y declara no haber lugar al retracto. Contra la referida sentencia de la Audiencia, la demandante $\mathrm{D}^{\mathrm{a}}$ Nuria Batet Martí interpone el presente recurso de casación a través de tres motivos, todos ellos por el cauce del ordinal quinto del artículo 1692 de la Ley de Enjuiciamiento Civil.

SEGUNDO.- El motivo primero, con la sede procesal ya dicha, acusa a la sentencia recurrida de infracción del párrafo $2^{\circ}$ del artículo 48 de la Ley de Arrendamientos Urbanos, al considerar caducada la acción de retracto, cuando lo cierto es, dice la recurrente, que la referida acción la ejercitó dentro del plazo que establece dicho precepto, si bien la demanda, por error, la dirigió contra quien en la escritura pública de compraventa había actuado como representante de la compradora, creyendo que él había sido el comprador. Para la resolución del único «thema decidendi» que plantea el pesente recurso(caducidad o no de la acción ejercitada), ha de partirse de que tanto la caducidad, como la prescripción extintiva (salvadas las diferencias que, en otros aspectos, existen entre ambas instituciones) descansan sobre la presunción de abandono de un derecho que entraña el no ejercicio del mismo por su titular dentro del plazo establecido para ello por la ley (o por la voluntad de los interesados), presunción 
de abandono que, lógicamente, queda desvirtuada e inoperante por el ejercicio del derecho dentro del plazo establecido, al ser conceptos ontológica y jurídicamente incompatibles los de caducidad y ejercicio temporáneo o cronológicamente oportuno (dentro de plazo) de la acción respectiva. Sobre la base de la anterior doctrina, el motivo ha de ser estimado, ya que la arrendataria del local litigioso, aquí recurrente, $D^{2}$ Nuria Batet Martí, al serle notificada (en 18 de Mayo de 1988) la compra que del referido local, por escritura pública de fecha 13 de Mayo de 1988, había hecho Da Ana-María Pascual Gonzalo, representada en dicha escritura pública por su padre D. Anastasio Pascual Ortega, ejercitó la correspondiente acción de retracto mediante demanda presentada en el Juzgado el día 15 de Julio de 1988 y, por tanto, dentro de los sesenta días que para ello establece el párrafo $2^{\circ}$ del artículo 48 de la Ley de Arrendamientos Urbanos, en cuya demanda quedó plenamente identificado el local objeto del retracto y la causa determinante de éste (la referida compraventa instrumentada en la ya dicha escritura pública de fecha 13 de Mayo de 1988), sin que el hecho de que, por haber entendido erróneamente que el comprador era D. Anastasio Pascual Ortega (representante y padre de la compradora), dirigiera inicialmente su demanda contra éste y luego rectificara dicho error, dentro del mismo proceso, ampliando su demanda y dirigiéndola ya contra la verdadera compradora ( $D^{\mathbf{a}}$ Ana-María Pascual Gonzalo), aunque esto último lo hiciera después de transcurridos los referidos sesenta días, pueda entrañar la caducidad del derecho de retracto, como aquí equivocadamente ha entendido la sentencia recurrida (en contra del criterio de la de primera instancia), pues el expresado derecho, como ya se ha dicho, fue ejercitado dentro del plazo legal (lo que ya incompatibiliza la producción de la caducidad) con plena identificación del local retraído y de la enajenación determinante del retracto, que lógicamente había de entenderse dirigido contra la verdadera adquirente o compradora del mismo (única legitimada pasivamente para soportar la acción del retracto), aunque por el error ya dicho se dirigiera inicialmente la demanda contra quien en la compra actuó como representante de la compradora que, además, fue quien requirió al Notario para notificar a la arrendataria la compra efectuada, cuyo error, como también ya se ha dicho, quedó subsanado oportunamente, dentro del mismo proceso y antes de que $D$. Anastasio Pascual Ortega (padre y representante de la compradora) evacuara el trámite de contestación, mediante la ampliación que la actora hizo de su demanda, dirigiéndola ya corectamente contra la verdadera compradora $D^{\mathbf{a}}$ Ana-María Pascual Gonzalo, que se personó y defendió en el proceso, por lo que hade entenderse que la acción de retracto fue ejercitada dentro del plazo y, por tanto, no producida la caducidad de la misma. La estimación del motivo primero, al que acabamos de referirnos, hace innecesario el examen de los motivos segundo y tercero, ya que éstos, por los que se denuncia la infracción, 
por no aplicación, del artículo 1618 de la Ley de Enjuiciamiento Civil (en el segundo) y del artículo 11, párrafo $3^{\circ}$ de la Ley Orgánica del Poder Judicial en relación con el artículo 24 de la Constitución (en el tercero), tienen el mismo objeto impugantorio que aquél, cual es el de combatir, desde otras perspectivas jurídicas, la declaración que la sentencia recurrida ha hecho erróneamente de caducidad de la acción.

TERCERO.- El acogimiento del motivo primero, con las consiguientes estimación del recurso y casación y anulación de la sentencia recurrida, obliga a esta Sala, conforme preceptúa el número $3^{\circ}$ del artículo 1715 de la Ley de Enjuiciamiento Civil, a resolver lo que corresponda dentro de los términos en que aparezca planteado el debate, lo que ha de hacerse en el sentido de mantener subsistente el «fallo» de la sentencia de primera instancia, que estimó la demanda y declaró haber lugar al retracto, pues aparte de la aducida, y aquí no aceptada, caducidad de la acción, y aparte de la igualmente alegada renuncia previa al retracto por parte de la arrendataria que, como ya se tiene dicho, fue desestimada por la sentencia recurrida y cuya desestimación ha consentido la demandada $D^{\mathbf{a}}$ Ana-María Pascual Gonzalo, aparte de ello, decimos, la tercera causa de oposición que la demandada hizo consistir en su alegación de incumplimiento de los requisitos para retraer, por no haber consignado la demandante los gastos del contrato y otros pagos legítimos hechos para la venta (honorarios de Notaría, impuesto de transimisiones patrimoniales, arancel del Registro de la Propiedad) y acerca de la cual no entró a conocer la sentencia recurrida (por haber estimado la caducidad de la acción), ha de ser igualmente desestimada, como hizo la sentencia de primera instancia, ya que es doctrina consolidada de esta Sala (Sentencia de 20 de Mayo de 1991, por citar alguna de las más recientes) la de que la obligación de consignar mencionada en el no 2 del artículo 1618 de la Ley de Enjuiciamjiento Civil se refiere únicamente al precio de la venta y no abarca los gastos del contrato y demás pagos legítimos, que pueden ser abonados con posterioridad, una vez que sean conocidos, habiéndose comprometido formalmente la retrayente en su demanda a abonarlos, como ha ocurrido en este supuesto, compromiso formal que, asimismo, contrajo respecto a las cantidades que posteriormente haya pagado la compradora con cargo a la parte de precio que retuvo con dicha finalidad; en cuanto a las costas de primera instancia ha de estarse a lo que resuelve la sentencia de dicho grado; no procede hacer expresa imposción de las costas de apelación, ni de las del presente recurso, sin que haya lugar a acordar la devolución del depósito, al no haber sido constituido el mismo, por no ser las sentencias de la instancia conformes de toda conformidad. 
Por lo expuesto, en nombre del Rey y por la autoridad conferida por el pueblo español.

\section{FALLAMOS}

QUE ESTIMANDO EL PRESENTE RECURSO, interpuesto por el Procurador D. Eduardo Morales Price, en nombre y representación de $D^{\mathbf{a}}$ Nuria Batet Martí, ha lugar a la casación y anulación de la sentencia de fecha diecinueve de Octubre de mil novecientos ochenta y nueve, dictada por la Sección Once de la Audiencia Provincial de Barcelona y, en sustitución de lo en ella resuelto, se mantiene subsistente el «fallo» de la sentencia de fecha catorce de Febrero de mil novecientos ochenta y nueve, dictada en este proceso por el Juzgado de Primera Instancia número Cuatro de Barcelona; las costas de primera instancia serán abonadas en la forma que determina dicha sentencia; no ha lugar a hacer expresa imposición de las costas de segunda instancia, ni de las del presernte recurso; líbrese a la mencionada Audiencia la certificación correspondiente con devolución de los autos y rollos de apelación remitidos. 


\section{COMENTARIO}

El comentario de la sentencia que nos ocupa, hace precisa una serie de previas consideraciones sobre temas básicos y archisabidos de derecho procesal. Aunque nunca esté de más recordar conceptos olvidados de tan manidos, como puedan ser los de acción y pretensión procesales.

Por acción, en su sentido más rudimentario y simplista, podemos considerar el derecho a obtener la actuación de los Tribunales. Esto es, el derecho a obtener una sentencia: sin más.

En este sentido ha venido insistiendo el Tribunal Supremo en considerar la acción como derecho a acceso a la justicia; afirmando que la tutela efectiva supone que los litigantes sean oídos y tengan derecho a una decisión en derecho, ya sea favorable o adversa. También en esta misma línea el Tribunal Constitucional, para el que el derecho de acción es tanto como el derecho a la tutela judicial.

En cuanto a pretensión, como señala Guasp, es una declaración de voluntad, pero no referida a un negocio jurídico, como en derecho privado, sino una declaración petitoria. En ella se reclama una cierta actuación del órgano jurisdiccional que especifica el pretendiente, $y$, por último es imprescindible al concepto de pretensión procesal que se interponga siempre frente a persona determinada y distinta del autor de la reclamación.

Son, pues, notas subjetivas de la pretensión, para dicho autor: a) Organo jurisdiccional territorial y funcionalmente competente. b) Sujeto activo de la pretensión, que habrá de contar con capacidad para ser parte y capacidad procesal, con la necesaria legitimación en causa, y con la oportuna postulación procesal. c) Sujeto pasivo de la pretensión, o persona contra quien se dirige éste; habrá de contar con capacidad para ser parte y con legitimación.

Dos primeras conclusiones podemos dejar sentadas: 1.- La acción procesal tiene como finalidad la de excitar, la de poner en marcha el aparato judicial; su naturaleza es, entonces, absolutamente procesal. 2.- La pretensión, basada en un derecho sustantivo, persigue una resolución judicial de reconocimiento del mismo.

Precisamente, la pretensión se formula, a manera de ariete contra quien discute, ignora, o se arroga el derecho que el pretendiente intenta obtener a su favor, de suerte que su característica más usual y destacada es la de «dirigirse contra».

Con referencia al retracto legal, dice el artículo 1.521 del Código civil que «es el derecho de sobrogarse, con las mismas condiciones estipuladas en el contrato, en lugar del que adquiere una cosa por compra o dación en pago».

Y si lo referimos al retracto urbano, nos dice el artículo 48 de la Ley especial: «En los mismos casos a que se refiere el artículo anterior, podrá el inquilino arrendatario ejercitar el derecho de retracto, con sujección a lo dispuesto en el artículo 1.518 del Código civil, cuando no se le hubiere hecho la notificación prevenida en el artículo precedente o se omitiere en ella cualquiera de los requisitos 
exigidos, resultare inferior el precio efectivo de la transmisión, menos onerosas las restantes condiciones de éstas o la transmisión se realizare a persona distinta consignada en la notificación para el tanteo. $==$ El derecho de retracto caducará a los 60 días naturales, contados desde el siguiente de la notificación que, en forma fehaciente, deberá hacer en todo caso el adquirente al inquilino o arrendatario de las condiciones esenciales que efectuó la transmisión, mediante copia de escritura.

También en este caso, el derecho de retracto, además de la cualidad de inquilino o arrendatario, nace de venta o cesión solutoria del bien en cuestión.

Un escalón más nos eleva lo anteriormente descrito en relación a la ilación que venimos siguiendo, cual es la necesidad de dirigirse el retrayente, precisamente, bien contra el adquirente de la vivienda o local, bien contra vendedor y adquirente. Pero siempre, dirigiendo su pretensión, ejercitando su derecho contra persona o personas en concreto y perfectamente conocidas y determinadas. De ello que no esté de más, un recordatorio a otros artículos del Código civil, como al 1.973 y siguientes, recogiendo del primero, para no alargarnos «La prescripción de las acciones se interrumpe por su ejercicio ante los Tribunales, por reclamación extrajudicial del acreedor y por cualquier acto de reconocimiento de la deuda por el deudor».

Abunda en ello, entre otros muchos, el artículo 524 de la Ley de Enjuiciamiento Civil, cuando al disponer que el juicio declarativo principiará por demanda, señala como uno de sus requisitos, la manifestación de la persona contra quien se proponga.

Dice al tenor la sentencia de 30 de diciembre de 1939: «El demandante, como dueño de la acción, puede dirigirla contra quien tenga por conveniente, designándola con claridad y precisión, sin que, en términos generales, y fuera de los casos de excepción que la ley admite como parte legítima en los autos a quien no ha sido expresamente llamado a ello, los Tribunales puedan tener por demandado, ni en consecuencia, por parte legítima para promover competencia, a persona distinta de la designada por el actor y citada a juicio».

También Manresa echa su cuarto a espadas, y escribe con respecto al nombre del demandado: «Conforme la ley con la jurisprudencia antigua, exige como requisito indispensable la designación de la persona contra quien se proponga la demanda, cuya designación deberá hacerse expresando su nombre y apellidos y domicilio y profesión $\mathrm{u}$ oficio... El actor debe tener sumo cuidado en esta designación para no hacer ilusiria su demanda... También debe atender a si aquél con quien trata de ejercitar la acción es o no el verdadero responsable a las resultas del juicio; pues si no lo fuera, se expondría a que fuese absuelto éste de la demanda... el demandante... puede también tener dificultad en designar la persona contra la que proponga la acción: esto sucederá cuando la persona obligada hubiese fallecido o transmitido a otro la cosa que ha de perseguirse por acción real. En tales casos, si el actor tiene duda sobre quiénes son los herederos o la persona que deba ser demandada, podrá preparar el juicio con la diligencia preliminar que autoriza el núm. $1^{\circ}$ del artículo $497 \ldots »$. 
Nota a destacar de este comentario, es la relativa a la, casi unanimidad de doctrina y jurisprudencia relativamente a considerar la acción retractual como de caducidad y no como de prescripción (el propio número 2 del artículo 48 de la L.A.U. lo manifiesta expresamente: «El derecho de retracto caducará...»). Valgan, como ejemplo de todas las innúmeras sentencias que distinguen entre significados, efectos y alcances de caducidad y prescripción, las siguientes: Para la de 18 de octubre de 1963: «Si bien las excepciones de prescripción y caducidad responden a una finalidad - la presunción de abandono de acciones, derechos y obligacionescuyos conceptos no aparecen estudiados en el Código civil, ha venido la doctrina jurisprudencial diferenciándolas entendiendo, como se dice en las de 27 de abril de 1940 y 15 de septiembre de 1950, que cuando la ley otorga un tiempo determinado para su ejercicio se está ante la presencia de un plazo de caducidad, pasado el cual el derecho dejó de existir, pudiendo ser deducida de los hechos que el litigante expone y acordarse de oficio, mientras que la prescripción, sólo se puede admitir cuando es alegada». Dice la de 28 de noviembre de 1983: «Los fundamentos que dan vida a la institución de la caducidad, y primordialmente por afectar la misma al interés general que depara la seguridad de las contiendas jurídicas evitando dilaciones innecesarias en el desarrollo de todo juicio civil, una vez transcurridos los plazos de caducidad fijados una acción, originan los correspondientes acuerdos y mandamientos judiciales de oficio, o sea, sin previa excitación de parte».

Asimismo merece la pena resaltar la pacífica aceptación por doctrina y jurisprudencia, de la naturaleza civil del plazo para el ejercicio del derecho de retracto que, por cierto y en la sentencia que nos ocupa, al tratarse de urbano, se concreta en sesenta días, desde el en que se notificó a $\mathrm{D}^{\mathrm{a}}$ Nuria, mediante carta con acuse de recibo, la venta del local de negocio del que era arrendataria; notificación, mediante copia de escritura, que llegó a sus manos el día 18 de mayo de 1988.

Largo tiempo meditó $\mathrm{D}^{\mathrm{a}}$ Nuria, pues hasta el día 11 de julio de ese año no presentó ante el Juzgado la oportuna demanda ejercitando el retracto (habían transcurrido cincuenta y cuatro días desde el en que recibiera la notificación). Demanda que dirigió contra $\mathrm{D}$. Anastasio, quien, como recordamos, había adquirido el local en nombre y para su hija $\mathrm{D}^{\mathrm{a}}$ Ana María, que no fue demandada, empero el tiempo de que disfrutó $\mathrm{D}^{\mathrm{a}}$ Nuria para leer, releer, y hasta para aprender de memoria, la notificación de méritos.

Mas ocurre que D. Anastasio, con anterioridad a la contestación de la demanda, adujo la excepción dilatoria de falta depersonalidad, en tanto era absolutamente ajeno al negocio, habida cuenta de ser su hija $\mathrm{D}^{\mathrm{a}}$ Ana María la compradora del local.

Antes de que $\mathrm{D}$. Anastasio procediera a contestar a la demandada, advertida $\mathrm{D}^{\mathrm{a}}$ Nuria por la excepción alegada por D. Anastasio, alegando haber padecido error al identificar a la compradora, amplió la demanda para dirigirla contra padre e hija. Naturalmente, habían transcurrido con creces los sesenta días desde la famosa notificación de la venta. 
Es difícil entender, después de lo apuntado anteriormente y en especial tras la referencia al artículo 524 de la Ley de Enjuiciamiento Civil, cómo pudo el Juzgado aceptar una ampliación que lo único que ampliaba era la adición de un nombre, además, en base a la feble y, desde luego, inexcusable alegación de haber padecido error en la identificación de la compradora. (Defecto, en todo caso, achacable no sólo a ella misma, si no también a su representación y defensa que con tan poco provecho e interés leyeron la notificación; hasta el extremo de hacer irresistible la sospecha de que no lo hicieron).

Ignorándose la vía que se siguiera para obtener esta anómala ampliación (no lo explica la sentencia) pudiera presumirse, como única posible, la de interpretar - a nuestro juicio abusiva y retorcidamente-el artículo 156 de la Ley de Enjuiciamiento Civil a medida de la necesidad. Dice tal artículo: «Podrán acumularse y ejercitarse simultáneamente las acciones que uno tenga contra varios individuos, o varios contra uno, siempre que nazcan de un mismo título o se fundan en una misma causa de pedir».

Pero resulta: $1^{\circ}$-- No existen varios individuos en el caso que estudiamos, sino uno solamente: la compradora del local; luego difícilmente se la puede tener a ella por una y varia. $2^{\circ}$.-La causa de pedir era el ejercicio de la acción de retracto del local, el cual no lo compran dos personas, lo hace una solamente: la hija de D. Anastasio. 3․-- Hemos dicho que sólo la prescripción es susceptible de interrupción, mediante requerimiento judicial, notarial o de otra forma, dirigido, precisamente, al que indebidamente $\longrightarrow$ discutiblemente - ostenta el derecho. La caducidad no es interrumpible y sólo susceptible de ejercicio dentro del plazo por el que se concede, y se ha de ejercitar dirigiéndola no «urbi et orbi», sino contra la persona contra quien se debe entablar la acción, contra el legitimado pasivamente. 4ㅇ.- Dirigir a los 54 días, la demanda de retracto contra la persona de don Anastasio como comprador y pasivamente legitimado, ignorando a la auténtica destinataria de la acción y pretensión, es decir a la compradora real (contra la que se dirigió la demanda transcurridos mucho más de sesenta días - la demanda se amplió contra $\mathrm{D}^{\mathbf{a}}$ Ana María, por escrito de 11 de noviembre de 1988, seis meses después de efectuada la notificación de la compraventa a la arrendataria) es como no dirigir la demanda contra nadie, pues el derecho de retracto dejó de existir por no haberse ejercitado contra la compradora en plazo legal.

Una solución no resuelta ni aludida en autos, pero, para nosotros, la única susceptible de impedir la caducidad de la acción de retracto, hubiera consistido en dirigir la demanda contra don Anastasio como legítimo representante de la compradora, como especificábase en la notificación a la arrendataria; y mantener esta tesis a ultranza, sin posterior ampliación de la demanda. De suerte que no hubiera habido interrupción alguna, ni peligro de caducidad de la acción. Ahora bien, dirigida la demanda contra D. Anastasio como comprador y pasivamente legitimado para soportar la acción, conducía, inexorablemente, a las dos consecuencias siguientes: 
Primera, a su absolución —como de hecho acaeció-; segunda, en íntima conexión con la anterior, la declaración de caducidad del derecho de retracto, por haberse dirigido a persona totalmente ajena al negocio origen de repetido derecho.

Seguramente, podría venir al caso la sentencia de 11 de mayo de 1983, en cuanto decía: «El plazo de caducidad, a diferencia de la prescripción, no admite interrupción del tiempo, de tal manera que establecida la interrupción, después de haber transcurrido, es improsperable».

Otra interesante cuestión es la que, citando a Serra, destacan Almagro Nosete y otros, manifestando: «en pureza al entrañar el ejercicio del derecho de retracto de dos compraventas, y siendo así que la segunda venta debería ser únicamente otorgada por el vendedor primitivo, debería ser tan sólo este último el único demandado. No obstante, la jurisprudencia del Tribunal Supremo... ha impuesto la exigencia de que la demanda se dirija tanto contra el vendedor primitivo que contra el comprador o sucesivos compradores. Diciendo, asimismo, que la legitimación activa corresponde al titular de un derecho de retracto; la pasiva al primitivo vendedor del inmueble, objeto del retracto y a los varios compradores, quienes vienen a constituir un litisconsorcio pasivo necesario.

Aunque perfectamente sostenible, discrepamos de la docta opinión de los citados autores en punto a haber de dirigir la demanda contra vendedor y comprador, y ello, además de por no ser en la práctica usual (la propia sentencia que comentamos ni siquiera se lo plantea, a pesar de no dirigirse la demanda contra la vendedora), por la dualidad de posturas mantenidas, respectivamente, por vendedor y comprador.

En efecto, dos son los efectos primordiales que se barajan en tono al tema en cuestión: el relativo a la resolución del contrato, y el que se decanta por la tesis de hallarnos ante un supuesto de subrogación del retrayente en lugar del adquirente.

El propio Código civil mantiene ambas hipótesis, al decir en el artículo 1.506 que la venta se resuelve por retracto legal, mientras se mantiene en el 1.521 que el retracto legal es el derecho a subrogarse en el lugar del que adquiere una cosa...

Si duda el propio Código, tanto más la doctrina, y así:

Mientras para Manresa es un derecho de subrogarse en el lugar del adquirente, es decir, tiende a convertir en verdadero adquirente a quien el retracto corresponde...

Opina Peña Bernaldo de Quirós que la tesis de la subrogación no tiene en cuenta que no es posible siempre sustituir en sus relaciones al adquirente con el enajenante.

Optando por vía distinta, rechaza Albaladejo tanto la idea de subrogación como la de resolución, argumentando que en el retracto no hay ni subrogación en el contrato de adquisición del dueño, sino que el retrayente adquiere del adquirente en virtud de una nueva transmisión de éste a él.

Una aproximación dilucidatoria el problema, revelaría dos caras del mismo fenómeno. Una de ellas circunscrita a dquirente y vendedor, derivada de un contrato que habrá de quedar resuelto. La otra, posibilitadora de que sobre las bases del contrato prístino, se asentara el retrayente. El vértice de ambas lo constituiría el precepto legal consagrador del proceso. 
Asaz interesante, la sentencia de 27 de Febrero de 1954, recoge de una parte la discrepancia que con Almagro Nosete y otro subrayábamos, y resalta, de otra, el acuerdo que con ello manifestamos en cuanto a las tesis que mantienen, caso de varias transmisiones. Dice la sentencia anunciada: «Siendo una acción real la de retracto, la declaración principal objeto de esta acción sobre la entrega de la finca y el otorgamiento de la escritura debe hacerse contra el demandado que está en posesión de la finca y sólo contra éste, pero sentado por la jurisprudencia en sentencias de 12 de febrero de 1949 y 28 de abril de 1953 de que el medio de que pueda prosperar la acción en los casos en que haya habido varias transmisiones, es que se dirija contra el primero y los sucesivos adquirentes, es indudable que tiene que dictarse un pronunciamiento sobre esos demandados, y esa declaración no puede ser otra que la que hace La Sala sentenciadora de que reconozca que ha lugar el retracto, ya que no es admisible que se admita su presencia en litigio como demandado, y no se dicte resolución sobre él, o tenga que ser necesariamente absuelto...».

Expresa la de 8 de junio de 1906: «Cuando el comprador de la finca que es objeto del retracto ha perdido su dominio por haberla enajenado a un tercero, es forzoso que la demanda se dirija conjuntamente contra ambos, pues dirigida tan sólo contra el primer comprador, no hay términos hábiles para que éste cumpla con ninguna de las obligaciones de subrogación que son consecuencia necesaria del éxito de la acción de retracto».

Por último, se pronuncia el Fundamento de Derecho Tercero de la sentencia que entretiene nuestra atención, sobre causa de oposición introducida oportunamente en el proceso por $\mathrm{D}^{\mathrm{a}}$ Ana María, basada en no haber cumplido la demandante los requisitos para retraer, por no haber consignado los gastos de contrato y otros pagos legítimos (honorarios de la Notaría, impuesto de transmisiones patrimoniales, arancel del Registro de la Propiedad), cuestión sobre la que no se manifestó la Audiencia Provincial de Barcelona, al acoger la caducidad de la acción. Sin embargo, en esta ocasión y en la sentencia que comentamos, se rechaza de plano tal postulación, arguyéndose que la obligación de consignar mencionada en el número $2^{\circ}$ del artículo 1618 de la Ley de Enjuiciamiento Civil se refiere únicamente al precio de la venta y no abarca los gastos del contrato y demás pagos legítimos que pueden ser abonados con posterioridad, una vez que sean conocidos.

Sabido es que el artículo 1.518 del Código civil, al que hace referencia el 48 de la Ley de Arrendamientos Urbanos, aunque en sede de retracto convencional, es de aplicación también al retracto legal por imperio del artículo 1.525 del propio Código; que el artículo 1.618,2 de la Ley de Enjuiciamiento Civil requiere, para que pueda darse curso a las demandas de retracto, que se consigne el precio si es conocido, o si no lo fuere que se de fianza de consignarlo luego que lo sea.

Siguiendo la doctrina jurisprudencial, armonizadora de los artículos 1.518 del Código civil y 1.618 de la Ley de Enjuiciamiento Civil, resulta: A) Para hacer uso del retracto es imprescindible, simultáneamente, la entrega o consignación del 
precio. B) Respecto de los demás gastos a que alude el artículo 1.518, no es de exigencia su satisfacción inmediata, sino que es posible llevarse a efecto posteriormente.

Siquiera provoca cierto sonrojo el sólo pensamiento de acercamiento desglosador al elenco del artículo 1.518, nunca viene mal tributar una prima al tópico, y de esta suerte: Los gastos del contrato a satisfacer son los realmente efectuados, de suerte que si no los hubo no existirá obligación alguna al propósito. El pago, ya lo dice el precepto, ha de ser legítimo, esto es, conforme a la ley, al contrato o a la costumbre. La opinión predominante se inclina por entender incluidas en el concepto de pagos legítimos, las cantidades desembolsadas con ocasión del antaño denominado impuesto de derechos reales, y excluidos los gastos del pleito que hubiera de seguir el comprador contra el vendedor para otorgamiento de la oportuna escritura pública, pues tales gastos se han de circunscribir a los litigantes, de cuya condición no participa el retrayente.

En torno'a gastos necesarios, es imprescindible que no sean los de simple conservación de la cosa u ordinarios, que correrían a cargo del comprador.

En lo atinente a gastos útiles, las motivaciones que se esgrimen para que su pago recaiga sobre el vendedor, se cimentan en que el comprador es, en principio, poseedor de buena fe, amparado por el artículo 453 del Código civil, por cuya virtud, los gastos útiles le deben ser abonados.

Contraria a la sentencia de 20 de mayo de 1991, que cita la en estudio, venimos a aducir por nuestra parte, la muy curiosa de 24 de mayo de 1982, disponiendo: «El retrayente hizo una defectuosa consignación del precio, pues no consignó además los gastos del contrato ni los demás procedentes, por todo ello es evidente que no se dan los presupuestos legales para la estimación de la acción de retracto que exigen los artículos 48 de la L.A.U. y 1.518 del Código civil».

Por tanto, nuestra conclusión es partidaria de solución distinta a la de la sentencia estudiada, y se decanta en pro de la dictada en apelación, recogiendo la tesis de la caducidad de la acción de retracto ejercitada. 